\title{
THE HISTORY OF OTORHINOLARYNGOLOGY AT THE CHARLES UNIVERSITY FACULTY OF MEDICINE IN HRADEC KRÁLOVÉ
}

\author{
Ivan Hybášek
}

ORL Department, Charles University, Faculty of Medicine, Hradec Králové; (Head: doc. MUDr. J. Vokurka, CSc.)

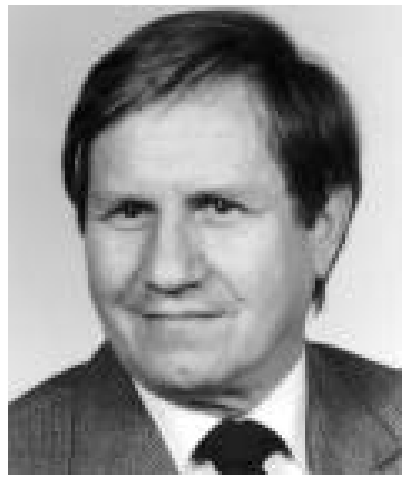

Professor I. Hybášek (1929)
The public health service inherited in 1918 by the Czechoslovak Republic at its inception from the Austro-Hungarian Monarchy, was among the more advanced in Europe. Its foundations were established by the General Health Ordinances of 1752 and 1753, and gradually also accepted by the Czech and Moravian congresses.

This document, still significant after almost twoand-a-half centuries, was concerned primarily with the prevention of serious infectious diseases, but also with some lay healing practices already quite widespread at that time. The General Health Ordinance was the basis for the building of public hospitals and maternity institutions. Such places were erected in Brno (1786), Olomouc (1787) and Prague (1790). Hradec Králové received its first city hospital in 1789 , which had to be moved from one location to another due to the geographic restrictions caused by the city walls. A new hospital, built outside the walled city near the river Orlice, was opened in 1887. This institution, which underwent several reconstructions, is still in use today. It was chaired from 1905 by a notable surgeon and health administrator, Chief Surgeon Dr. Honzák, who was also responsible for the professional diversity of the hospital.

It was through his influence that - in addition to medicine, surgery, obstetrics and ophthalmology - the department of ORL was established in 1925.

The discipline of ORL has its own interesting story mainly due to its three cornerstones that gradually melted into one harmonic unit. In the middle of the 19th century otology had split from surgery, and laryngology has developed out of internal medicine. Somewhat later the discipline of rhinology was added owing to the necessity to treat diseases of the upper respiratory tract. The unifying link of these disciplines, in addition to the underlying common pathology of inflammation, was the technique of endoscopy. Its basis was the discovery in 1841 of the light-reflecting mirror by Hoffmann, a German practitioner from Ochsenfurt.

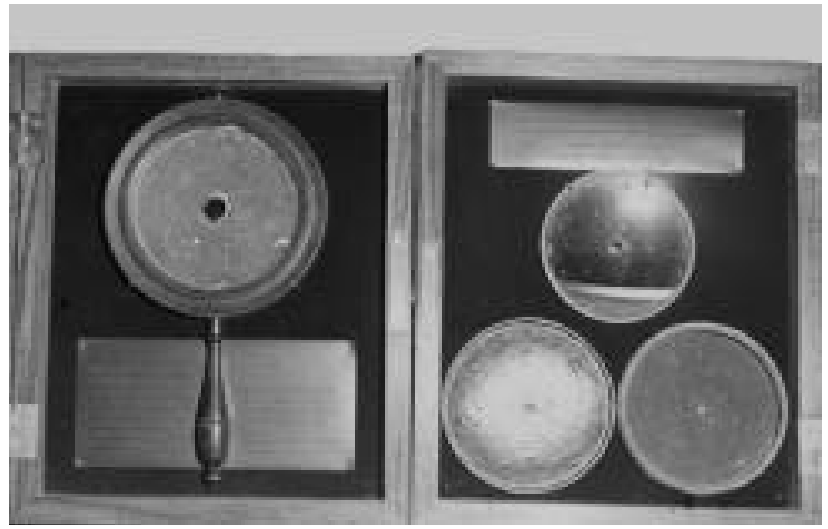

Light-reflecting mirror constructed by Hoffmann (1841) and von Troeltsch (1853).

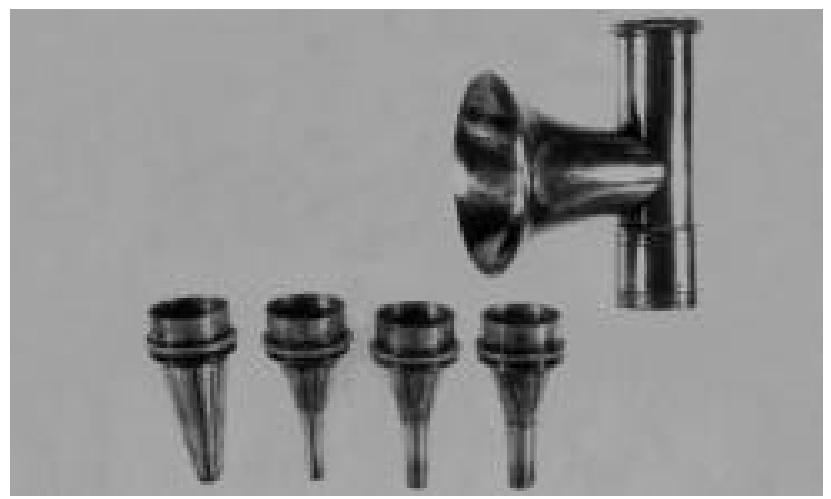

The first otoscope constructed by Brunton (1865).

The laryngoscopic mirror, discovered in 1855 by Garcia to study the vocal cord of singers, was introduced into clinical practice a year later by the physiologist Jan Nepomuk Čermák, who was a pupil of Purkyně. Čermak also broadened the diagnostic methods in ORL by the introduction of indirect epipharyngoscopy.

The unification of all branches of ORL dates back to the turn of the 20th century. Czech otology established its first clinic at the Charles University in Prague in 1892, and laryngology did the same in 1906.

In the same year also the Free Association of Czech Otorhinolaryngologists was founded, which was the predecessor of the current Czech Society for Oto-Rhino- 
Laryngology and Surgery of the Head and Neck. As mentioned, The ORL department in Hradec Králové was established in 1925; it was the first such institution outside the Czech capital. Its first physician-in-chief was Dr. Václav Tesař, a pupil of Professor Kutvirt in Prague, who was an eminent surgeon during the First World War, and author of a several of scientific papers. In 1929, after the erection of a new district hospital, ORL moved into a new building with 54 beds, 2 operating rooms and an emergency room. In 1939, after the completion of the hospital reconstruction, the number of ORL beds was increased to 104. This, in its time modern and well equiped workplace, became the basis for the University Department of ORL, after the creation of the Faculty of Medicine at Hradec Králové, by decree of October 13, 1945, signed by President Beneš. This was the third medical school after Prague and Brunn (Brno). The foundation of the Faculty of Medicine in Hradec Králové was facilitated by the fact that there were some department chiefs already with the rank of associate professor, who were able to recruit to the new medical school other scientifically, professionally and pedagogically endowed physicians from Prague and Brunn, who were already qualified and appointed teachers in clinical and theoretical disciplines. Hence the Associate Professor Jan Hybášek from Brunn was recruited by the local Drs Bedrna, and Maršálek. Jan Hybášek was known not only as an excellent and avantgarde surgeon, but also as an educator and scientist; in addition, he was a capable graphic artist and painter who, after the First WW, still as a medical student in Brunn, began to compile pictorial material for the departments of pathology and particularly of ORL at the new Faculty of Medicine. This talent along with a good visual memory and imagination made him famous as a teacher; he was able to create before the eyes of his students a central theme of his lectures with the aid of color crayons. And since ORL is based mainly on visual demonstration, Hybášek's lectures were always packed with students. His talent as a fine artist contributed to the excellent quality of his own textbooks; it also complemented his excellence in functional and restorative surgery.
The period under Professor Jan Hybášek, M. D., D. Sc. (1946-1962)

The history of the ORL department as a teaching institution started on Jan 1, 1946, when Professor Hybášek - as its first chairman - presented a clear idea and plans for the future layout and workings of the department. Dr. Hybášek had this ability not only from his own experience in establishing and later directing the University ORL Department in Brunn, but also due to his own organizational talent and invention, and particularly due to his enthusiasm and endurance. His arduously pursued intentions were oriented toward the innovative use of space in the ORL department, and its equipment with modern technology for clinical activity. Hybášek strove for the organization of sections and of the entire department in order to provide all avenues for diagnostics and therapy of patients with ORL diseases, and for the teaching of medical students and the postgraduate training of young physicians. He put his effort toward scientific work, and toward the cooperation with specialists and generalists in the region, including their postgraduate education. $\mathrm{He}$ also devoted serious effort to participate in the overall life of the medical school. Hybášek was not alone; he brought with him Dr. Ervin Černý, a recent graduate from the medical school in Brunn, and the experienced head nurse Antonie Žejdlíková. These two coworkers became Hybášek's unique and irreplaceable collaborators during the many years of building and developing the department.

Dr. Černý, known for his dexterity and also talented in fine arts as Hybášek, created collections of medical drawings and paintings, while he also prepared plans for the interior design of the department and its reconstruction. It may be premised here that Dr. Černý gradually grew into a personality of his own in Czech ORL circles, becoming a Dr. of science and professor, and an author of (among others) the renown atlas „Surgery of the Ear.“ In his free time he was also dedicated to historic geography and discovered in Moravia several abandoned hamlets and habitations from the Middle Ages. In this discipline - originally only

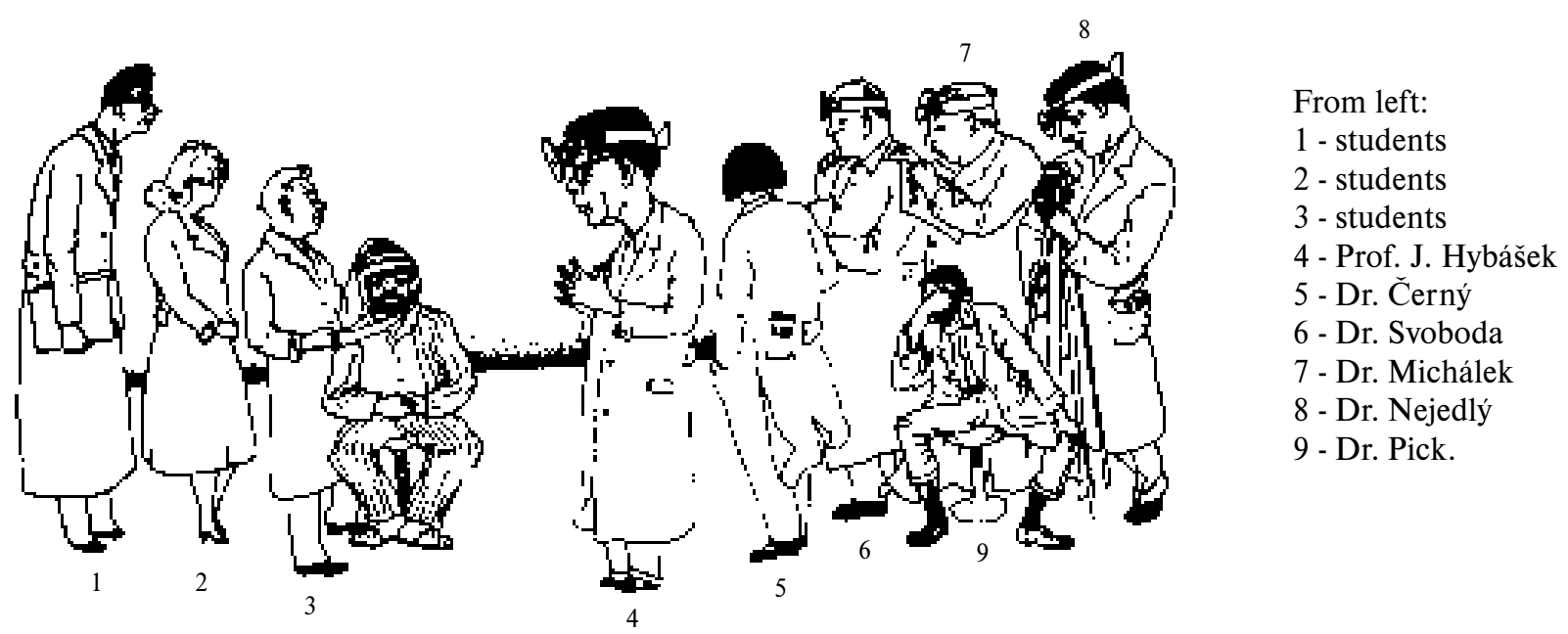

Caricature of the first generation of physicians at the ORL Department in the year 1947 (drawing by E. Černý). 
a hobby - he also published sound scientifically materials that granted him another academic degree.

In addition to the above named, there were four other physicians who worked at the ORL department and who participated in the activities. However, they directed their efforts more on becoming specialists in the field of ORL, and indeed by 1950 they had left the university to become ORL physicians-in chief at other hospitals.

For the clinic and the hospital with 75 beds it was necessary to build an X-ray facility, laboratories for biochemistry, morphology and physiologic function, teaching accommodations with an auditorium, and at least the rudiments of a library. That, however was financially not feasible in a warravaged and economically struggling Czechoslovakia, hence the solution of some of these problems rested mostly on the individual enthusiasm and devotion of Dr. Hybášek and his collaborators. We now feel great admiration for all what this early generation of clinicians had accomplished: they planned and made projects, they procured material, manufacturers, as well as medical material. They assisted with management plans, they founded an educational museum and a teaching facility, for which they created and hand-prepared teaching aids and specimens; they felt honored whenever they could present any novelty in diagnostics, therapy or teaching. It is worthwhile mentioning that the organization of the daily activity and its functional diversity in the ORL department and clinic conceived and introduced by Hybášek over 50 years ago, was so perfect that it remained in effect till the present, with only insubstantial changes.

If Jan Hybášek during this early period of the University Department of ORL continued in his scientific activity with the work initiated at the Brno (Brunn) Medical Faculty (i.e. restorative and functional surgery of the middle ear, intracranial complications and septicemias in ORL, surgery of laryngeal cancer), Dr. Černý embarks on the problems of vestibular function and equilibrium; he gradually orders the manufacture of rotation chairs, slanted tables, linear swings and other equipment. For completeness one has to add that the results of this arduous scientific work were compiled into a doctoral thesis after almost 50 years.

In the late fifties, the first generation of physicians, except for Dr. Černý, had left the ORL department and were replaced by young physicians, graduates of the Faculty of Medicine in Hradec Králové.

Professor Hybášek, as a prominent educator, always attracted young physicians, and there were always many applicants for the few positions available. Hybášek had a very effective selection process for new coworkers; it is remarkable even today to browse through Hybášek's and Černý's detailed study-and-examination protocols of medical students, which aided them in their decision whom to pick among the applicants. In these notes one can find not only a detailed description of the students' actual knowledge, but also their mode of expression and behavior, an assessment of the students'character and enthusiasm for medicine, and the prediction for success in the specialty. I may not come as a surprise that almost all new doctors gradually became highly qualified specialists and surgeons with great skills, renown scientists and educators. All physicians of this group (Faltýnek, Semerák, Nejedlo, Novák) became scientists (Ph.D.) and university teachers; some of them reaching the highest rank in science (D.Sc.) and education (full professor).

The usual breadth of the enterprise, encompassing next to classic filed of ORL also pediatric ORL, phoniatrics, logopedics, audiology, labyrinthic function, peroral endoscopy, plastic, functional and restrictive surgery, attracted several other otorhinolaryngologists (Fajstavr, Zbořil, Ivan Hybášek).

They too later became appointed associate professors and full professors as well as department heads. The dicovery and the introduction of antibiotics after Second World War substantially changed the practice of ORL due to a great reduction in infections, whose successful treatment prevented the development of complications and the subsequent need for surgical interventions. This trend enabled the physician staff to concentrate more on functional and restorative surgery. Professor Jan Hybášek was known as a modern, very exact ear and throat surgeon, thus it was obvious that he refined those surgical procedures that preserved or renewed the function of these diseased organs. In the fifties Dr. Hybášek was only one step away from tympanoplasty and the successful treatment of otosclerosis, and from horizontal laryngeal resection in lieu of the frontal type. These steps were undertaken virtually in unison with their discovery at other workplaces in the world.

A great gift of observation brought Hybášek to the study of spontaneous tympanoplastic structures, which the organism develops to defend itself against ear infections (11). On that bases he designed his own concept of minimal restorative and reconstituing procedures that protected all structures capable of self restitution, by creating the least number of surgically bare surfaces, and utilizing - except for stapes surgery - tissue grafts taken from the patient. Despite immense obstacles in procuring optical apparatus and tools for microsurgery, which Professor Hybášek mostly constructed himself, he obtained excellent results, comparable to other top international medical centers.

Surgery for otosclerosis had been initiated in Hradec Králové in 1949, and tympanoplasty was introduced in many aspects already in 1951, independent on H. Wullstein and F. Zoellner, the founders of tympanoplastic surgery. In this field Professor Hybášek and his coworkers achieved a number of priorities, as later confirmed by Professor Wullstein himself before an audience of an ORL congress in Hradec Králové, where he admitted that he had to quickly change his views about coming to teach, because he himself had to learn a lot in Hradec Králové.

Great progress in tympanoplasty has been achieved due to the experimental work performed by Dr. Faltýnek on the function of labyrinthine windows; by Dr. Nejedlo on the healing processes after the transfer of skin grafts; and also by Dr. Ivan Hybášek on the pathogenesis of chronic middle ear infections and post/inflammatory conditions $(6,12)$. These works found theoretic, methodologic and fiscal support from the Institutes of Physiology, Anatomy, Histology and 
Forensic Medicine at the local Faculty of Medicine, and often numerous authentic data was obtained by direct personal collaboration.

At the time the department had been concentrating on upper respiratory diseases, in part also in connection with functional problems of the auditory tube in patients with chronic inflammation of the middle ear and its sequalae. It was Dr. Semerák's merit that contralateral rhinomanometry was introduced, first experimentally, later also in practice; rhinomanometry was able to indicate the size of the lesion and the extent of procedures needed to correct not only the nasal septum, but also the nasal apertures (16). Somewhat later, Dr. Fajstravr studied the problems of the ciliary epithelium and clearance of the nasal cavity. These workers built their own rhinological laboratories at the clinic and also cooperated with the theoretical institutes at the medical school, particularly with the Institute of Biology, and Physics.

One cannot unmentioned the huge educational work almost exclusively authored by Jan Hybášek, as well as its accompanying schemes, drawings and color pictures. Altogether Hybášek published three teaching texts and five textbooks. He also contributed with his illustrations to texbooks of other authors. But his main opus remained the establishment of the University Department of ORL at the Faculty of Medicine in Hradec Králové; five of his pupils became professors and university department heads. However, if we look at these men, it is surprising, how little they resembled their teacher, and for that matter, each other. Nevertheless, it was they who individually and together established a complete and accomplished school of ORL, who wrote and keep writing the history of the Hradec Králové University Department of ORL; both individually and through their students. The fact that Professor Hybášek did not mold his pupils in his own image explains, why these men were able to pursue their own diverse but fruitful and original profesional careers. And that also gives expression to the great respect these personalities feel toward their teacher.

Professor Hybášek was disappointed with the times he lived in; he was troubled by the transformation of the Faculty of Medicine into a Military medical academy in 1951; he was involuntary relieved of the chairmanship of the University ORL Department for two years, during that time Dr. Černý was in charge of the department. After the termination ot the military academy and after the renewal of the Faculty of Medicine, both Hybášek and his department suffered from the restrictive policies of the university leadership. Dr. Černý left the department in 1958, to become the head of the ORL Department of the Central Military Hospital in Prague. Dr. Semerák, whom Hybášek considered his successor, was not a Communist and hence could not take over the chairmanship for political reasons. All this ultimately forced Hybášek into early retirement at the age of 63 .

The period of Professor Lubomír Faltýnek, M. D., D. Sc. (1962-1971)

Following the departure of Professor Hybášek, his pu- pil, Associate Professor Faltýnek became the new chief of the ORL Department. Unfortunately, the excellent team of professionals and scientists partially fell apart; among others, Drs Semerák and Nejedlo had left, and mostly young female physicians fresh out of medical school started working in the department who could not devote their entire day to the rigors of the schedule. Dr. Faltýnek, in cooperation with the Institute of Physiology, namely with Dr. Veselý turned his attention to the study of evoked auditory potentials $(3,4)$; Dr. Zborril studied the functions of the laryngeal muscles by electromyography (20), and Dr. Ivan Hybášek devoted his studies to experimental histopathology of the middle ear $(5,6,7)$. Dr. Ivan Hybášek won a stipend of the prestigious German Foundation of Alexander Humboldt, and between 1969-1970 has worked at the ORL clinical department of Professor Wullstein in Wuerzburg, West Germany. From that endeavor stemmed his work on the pathogenesis of tympanosclerosis and cholesteatoma $(9,10)$. Dr. Dürrer, a new arrival at the department, devoted his studies to traumalogy of the skull base and to the chain of the auditory ossicles $(1,2)$. In the surgical disciplines the restorative procedures of partial laryngectomy, surgery of the hypopharynx and middle ear were refined.

The political development in connection with democratization process (called Prague Spring) and its supression in 1968 led to mounting pressure upon department heads to resign. Also Professor Faltýnek was forced to resign from the chairmanship of the ORL Department in 1971, which was transitionaly demonted as an independent entity.

\section{The period of Professor Ivan Hybášek, M.D., D. Sc., (1971-1995)}

During this period the author of this article (I.H.) was instituted as chief of the ORL Department. Due to the defeat of the democratic forces in Czechoslovakia, a large part of the intelligentsia, particularly physicians, emigrated or voluntarily left the uncertain soil of the university; either in practice, or to become chiefs of non-university hospital departments. The Hradec Králové ORL Department went through similar difficulties: only three qualified physicians remained. It took a full decade to train and educate new specialists, and to bring the field of ORL to its new heights. At that time the department chair received full assistance only from a handful of coworkers; among them was Dr. Pellant who through his tenacity and diligence quickly established himself as a capable surgeon, specialist and scientist. After achieving his Ph.D. degree, he was appointed as an associate and then a full professor of otorhinolaryngology. Scientifically he pursued the problems of ultrasound diagnostics of the neck soft tissues, and later he tackled the problems of hearing loss in chronic nephropathies, particularly in the Alport syndrome $(14,15)$.

However, the pursuit of truly experimental research had gradually diminished and scientific work, mostly due to a total lack of funds for equipment and modernization, was mostly clinical. 
At the time, particular attention was paid to neoplasic diseases, both in their prevention and early detection, as well as in diagnosis, therapy, and subsequent care and rehabilitation. In the late seventies biologic tracheopharyngeal shunts - neoglottis phonatoria - had been well established and were routinely performed. The sublabial, transseptal approach for the extirpation of hypophyseal tumors was introduced, and surgical techniques were directed toward the surgery of the salivary glands, the facial nerve, and to facial trauma. In cooperation with the surgeons, esophageal replacemnet in resection due to cancer was performed with the technique of tubulated large curvature of the stomach.

By then the professional qualification of the physicians in the department was successful. New workers had been selected from the medical students who performed scientitic work at the department during their student years. By this way also Dr. Vokurka, who as a student worked on the problem of surgical approaches to the temporal sections of the facial and acoustic nerves, came to the ORL in the late seventies. In the eighties it became feasible to further qualify the full-time physicians in the department, and establish new concept of the specialty that exceeded its traditional limits.It was possible to concentrate also on the aspects of plastic and esthetic surgery, to establish a neuro-otologic laboratory and an allergy section. Tympanoplasty was extended and refined, and preparations were made to enter the era of functional endonasal endoscopic surgery (FES) in the late eighties. Regardless of the fact that Ivan Hybášek was the ideological and methodological architect of a number of surgical procedures introduced in the department, it was principally Dr. Vokurka who became the actual achiever of those methods. This was perticularly true with modern rhinosurgery, in which the department rapidly reached such excellence that it could - also in gratitude to the WOLF Company who provided the ORL Department with modern medical tools and equipment - organize since 1990 once or twice a year postgraduate courses in this discipline; first for beginners and later also for advanced, domestic and foreign participants. The department also participated in the organization of similar courses in Germany, Sweden, Italy and Slovakia. FES was later expanded - also due to the good cooperation with ophtalomogists and neurosurgeons - by endoscopic dacrycystomy and endoscopic decompression of the orbit and optic nerve; by FES the base of the anterior cranial fossa could also be reached. Endoscopic adenotomy became a significant improvement because it qualitatively advanced a procedure old 130 years (18).

Due to futile attempts at functional restoration of the recurrent nerve damaged during goiter surgery, Dr. Vokurka, in the mid eighties, began to study the operative procedure itself. Hence the ORL Department started performing thyroidectomies, and soon thereafter it was successful in reducing the occurrence of permanent recurrent nerve palsies far below 1 per cent (19). To this day strumectomies belong to the main activities of the department, and particularly in tumors of the thyroid oncologically excellent results have been achi- eved. Since the beginning of the nineties attention has also been directed to the surgical treatment of obstructive sleep apnea, and to rhonchopathies, qualitatively new procedures have been selected in phonosurgery. The department is equally in synch with modern trends in tympanoplasty.

Clinical material is added to the research activity, particularly in the filed of oncology and functional restorative surgery. Dr. Vokurka studied experimentally the tolerance of the membranous labyrinth to pressure (17), obtained his Ph.D. and later became associate professor after defending his thesis on functional rhinosurgery. Dr. Chrobok studied the prenatal and perinatal pathology of the membranous labyrinth in the inner ear (13). Further studies were dedicated to the problems of tympanometry, objective audiometry and otoacoustic emissions, and to the innovative exploits of stochastic resonance in hearing. The Hradec Králové University Department of ORL, once again moved to the front of Czech otorhinolaryngology and became a sought after center for long-term training, which included many applicants from abroad.

This endeavor was greatly aided by the expansion of the department into a new wing in the late eighties, which created improved conditions for the function of the phoniatric, audiologic and neurootologic sections, and the founding of clinical consultation rooms in rhinology, allergology and otology. The computer network was enlarged, and an hygienic and overall more comfortable environment for the patients was created. Gradually also the operating rooms were reconstructed, equipped with air-conditioning, modern sterilization technique, new operating tables and illumination; a surgical laser was installed as well as the newest models of operting microscopes and endoscopes, all connected via video. A new sleep laboratory was established and the labs for nystagmography and audiology were modernized. An intensive care unit was added. A laboratory for microscopic and endoscopic specimens preparations was established for teaching purposes.

The balance of all scientific publications during the over 50 years of the existence of the ORL Department exceeds 800 original articles; one has to add to this number several hundred additional scientific communications and 6 monographs. In the recent evaluation period I. Hybášek himself or with his coworkers has published 3 teaching texts and 2 textbooks. The department on the basis of its research activities has organized over 160 meetings, and 34 conferences and congresses lasting more than one day, many with international participation.

It is impossible to evaluate the activity of the department without reflecting on the political atmosphere of the times before November 17, 1989. I. Hybášek, A. Pellant and J. Vokurka stood in opposition to communism; it was obvious that they had difficulty in finding support for the needs of the department; actually, the opposite was true. To be able to employ a prospective physician who was not a Communist, or to procure a new medical appliance - was considered a near miracle. All these workers had to wait for many years to be permitted to defend their doctoral theses, 
as well as for their appointments to the university. Often they also had to give up their travels abroad and contacts membership in international ORL societies.

After November 1989 the work of the ORL Department was fully appreciated in the Czech Republic, as well as internationally. I. Hybášek was twice elected president of the Czech Society for Otorhinolaryngology, Head and Neck Surgery, and many honorary memberships were bestowed upon him at home and abroad. Dr. Hybášek represented until 1996 the Czech Republic in the Executive boards of International and European Federation of ORL Societies, and he is a member on editorial boards of several medical journals. His biography can be found in the pages of Medical Sciences International „Who’s Who“.

\section{Period of Associate Professor Jan Vokurka, M.D., Ph.D. (since 1995)}

In the fall of 1995 Ivan Hybášek retires and the ORL Department enters a new period. Jan Vokurka wins the contest for chairmenship of the ORL Department, he is a representative of modern concepts in the specialty, and becomes the scientific secretary of the Czech Society for Otorhinolaryngology, Head and Neck Surgery, and a member of the most prestigious international academy of ORL, called Collegium Oto-Rhino-Laryngologicum Amicitiae Sacrum. But neither he has it easy; transformation of the Czech health services after November 1989 does not make the activity of university hospitals attractive enough, so the most qualified physicians leave the university for the more lucrative private practice. After the virtual disintegration of the existing surgical and scientific team, Vokurka, similar to his predecessors, had to recruit new talent for the profession.

It appeard that also Vokurka was lucky in making the right choices, and the department, its students and the patients can expect new personalities of Hybášek's, Černý's, Semerák's or Faltýnek's stature. For the new adepts of the ORL profession Dr. Vokurka has prepared remarkable new projects and unprecedented chances for diagnostic and surgical endeavors that attract also physicians from abroad.

\section{References (selected)}

1. Dürrer J. Mechanism of the laterobasal fractures. Acta Otolaryngol (Stockh) 1968;66:25-32.

2. Dürrer J. Mechanical changes of the ossicular chain due to head injury. Pract Oto-Rhino-Laryng 1970;32:293-6.

3. Faltýnek L. et al. Zur Restitution der Mikrophonpotentiale des Meerschweinchens nach kurzfristiger Lärmbelastung. Arch Ohr Nas Kehlk Heilk 1964;183:190-7. 4. Faltýnek L. Electrical response of the guinea pig cochlea to click in noise and hypoxia conditions. Activitas nervosa 1965;2 (Suppl 7):158-9.

5. Hybášek I. Über das Cholesterolgranulom bei Mittelohreentzündungen. Mschr Ohreheilk 1965;99:359-65.
6. Hybášek I (ed.). Problems of the middle ear pathology and tympanoplasty surgery. Sb Ved Pr Lek Fak Univerzity Karlovy Hradec Králové (in English and German) 1966;9:135-279.

7. Hybášek I (ed.). Pathology and therapy of the ear nose and throat. Sb Ved Pr Lek Fak Univerzity Karlovy Hradec Králové (in English and German) 1969;12:115-212.

8. Hybášek I et al. Collection of scientific papers: 1. Pathology, clinical aspects and surgical treatment (FES) of rhinosinusitis chronica. 2. E.N.T. intracranial, orbital and septic complications. In: Otorinolaryngol (Prague) (in English) 1994;43:60-1374.

9. Hybášek I. Experimentelle Calcinose der Mittelohrschleimhaut bei den Meerschweinchen. Arch Klin Exp Ohr Nas Kehlk Heilk 1971;200:209-17.

10. Hybášek I. Bemerkungen zur ätiopathogenese des Mittelohrcholesteatoms. In: Hischberg J et al. (eds). Paediatric otorhinolaryngology, Budapest, 1988:159-160.

11. Hybášek J. Das anatomische und funktionelle Bild der im Verlauf der chronischen epitympanalen Entzündungen entstandenen spontanen Tympanoplastiken. Z Laryngol Rhinol Otol 1960;39:596-611.

12. Hybášek J, Hybášek I. Etiopathogenesis of so-called idiopathic hemotympanum and its relation to morphogenesis of the adhesive process. Acta Otolaryngol (Stockh) 1961;53:429-41.

13. Chrobok V, Šimáková E. Temporal bone findings in trisomy 18 and 21 syndroms. Eur Arch Otorhinolaryngol 1997;254:15-8.

14. Pellant A et al. Zur Frage der Schwerhörigkeit bei hereditären nephropathien. In: Paediatric otorhinolaryngology. Eds. Hirschberg J et al. Budapest, 1989:218-221.

15. Pellant $A$ et al. Gemeinsame Entwicklungsanomalien des Ohres und der Nieren. Oto Rhino Laryngol Nova 1995;4:32-5.

16. Semerák A. Objektive Beurteilung der Nasendurchgengigkeit. Z Laryngol Rhinol Otol 1958;37:248-54.

17. Vokurka J. Tolerance of membranous inner ear structures to pressure. Sb Ved Pr Lek Fak Univerzity Karlovy Hradec Králové 1989;32:57-80.

18. Vokurka $\mathrm{J}$ et al. Adenoidectomy as an endoscopic surgical operation. Cesk Pediatr 1995;50:620-2.

19. Vokurka $\mathbf{J}$ et al. Functional surgery of thyroid diseases at the E.N.T. University Department in Hradec Králové. Cesk Otorinolaryngol Foniatr 1992;41:257-61.

20. Zbořil M. Elektromyographie der inneren Kehlkopfmuskeln bei verschiedenen Phonationstypen. Arch Ohr Nas Kehlk Heilk 1965;184:443-9.

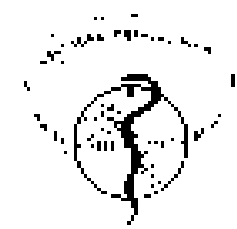

Prof. MUDr. Ivan Hybášek, DrSc., ORL Department Charles University, Faculty of Medicine, 50005 Hradec Králové, Czech Republic. 